\title{
Políticas Curriculares para o Ensino Médio e para a Educação Profissional: propostas, controvérsias e disputas em face das proposições do Documento Referência da Conae 2014
}

\author{
Curricular Policies to High School and Professional Education: \\ proposals, controversies and discussions in the face of Conae \\ 2014 Reference Document
}

Políticas Curriculares para la Escuela Secundaria y para la Formación Profesional: propuestas, controversias y conflictos frente a las proposiciones del Documento de Referencia de la Conae 2014

\section{Márcio Luiz Bernardim Monica Ribeiro da Silva²}

\section{Resumo}

O texto traz uma análise das proposições de políticas para o Ensino Médio e para a Educação Profissional Técnica de Nível Médio, com ênfase para a formulação de diretrizes curriculares. Toma por referência as proposições presentes no contexto da discussão da Lei de Diretrizes e Bases da Educação em torno da ideia de formação tecnológica, formação politécnica ou formação integrada, assumidas aqui como correlatas. Analisa, além das proposições presentes na LDB de 1996, os textos oficiais que tratam da matéria, notadamente os exarados pelo Conselho Nacional de Educação, em dois momentos distintos. O primeiro, quando da proposição das Diretrizes Curriculares de 1998 e 1999 e o segundo, quando da revisão e reformulação dessas Diretrizes, entre os anos de 2011 e 2012. O estudo mostra um embate de concepções e uma disputa por projetos societários e educativos que marcam a formulação dessas políticas curriculares. Tais embates e disputas são analisados à luz do Documento Referência da Conae 2014.

Palavras Chaves: Políticas Curriculares; Ensino Médio; Educação Profissional Técnica de Nível Médio; Diretrizes Curriculares.

\footnotetext{
1 Professor Adjunto da Universidade Estadual do Centro Oeste (UNICENTRO). Doutor em Educação pela Universidade Federal do Paraná (UFPR). E-mail: marcio. bernardim@gmail.com
}

2 Professora Associada da Universidade Federal do Paraná (UFPR). Doutora em Educação pela Pontifícia Universidade Católica de São Paulo (PUC-SP). E-mail: monicars@ufpr.br 


\begin{abstract}
The text brings an analysis of the policy propositions to High School and to Technic Professional High School Education, focusing on the curricular guidelines formulation. It takes as reference the present formulations found within the context of the Education Guidelines and Basis Law about the idea of technological, polytechnic or integrated formation, which are assumed here as correlated. It analyses, besides the propositions that are in the 1996 LDB, the official texts that deal with the subject, notedly the registered by the National Council of Education ones, in two distinct moments. The first one, by the time of the proposition of the Curricular Guidelines in 1998 and 1999; and the second one, by the time of the reformulation of the same guidelines, between 2011 and 2012. The study shows an opposition of conceptions and a dispute for societary and educative projects that determine the elaboration of those curricular policies and that are present in the Conae 2014 Reference Document.

Key words: Curricular Policies; High School; Technic Professional High School Education; Curricular Guidelines.
\end{abstract}

\title{
Resumen
}

El texto ofrece un análisis de las propuestas de políticas de Educación Secundaria y Formación Profesional de Técnica de nivel secundário, con énfasis en el desarrollo de los lineamientos curriculares. Toma por proposiciones las referencia presentes en el contexto de la discusión de la Ley de Directrices y Bases de la Educación sobre la idea de formación tecnológica, formación politécnica o entrenamiento integrado, asumidas aquí como relacionada. El artículo analisia, además de las propuestas actuales en 1996 LDB, los textos oficiales que se ocupan de la materia, en particular los formalizados por el Consejo Nacional de Educación, en dos momentos diferentes. El primero, cuando de la proposición de las Directrices Curriculares de 1998 y 1999 y el segundo, en la revisión y reformulación de las presentes Directrices, entre los años 2011 y 2012. El estudio muestra un choque de ideas y un concurso de proyectos de sociedad y educativos que marcan la formulación de estas políticas curriculares. Tales conflictos y disputas son analizadas frente al Documento de Referencia de la Conae 2014.

Palabras-clave: Políticas curriculares; Enseñanza secundária; Educación técnica de nivel secundário; Directrizes curriculares.

\section{Introdução}

Atualmente pouco mais de $50 \%$ dos jovens cursam o Ensino Médio na faixa etária adequada, além do que cerca de $35 \%$ dos matriculados estudam à noite e muitas vezes em precárias condições. De acordo com o Censo Demográfico de 2011, o Brasil possui 10,3 milhões de jovens entre 15 e 17 anos, dos quais apenas 5,4 milhões encontram-se matriculados na última etapa da educação básica. Aproximadamente 3 milhões e 300 mil encontravam-se, em 2012, matriculados no Ensino Fundamental e pouco mais de 1 milhão de jovens nessa faixa etária estavam fora da escola, em que pese pertencerem à faixa etária de escolaridade obrigatória. A matrícula total na última etapa da Educação Básica é de 8.312.815, conforme mostra o censo escolar de 2013 (INEP, 2014), indicando que um número bastante expressivo de estudantes desta etapa possui mais de 17 anos.

Com relação à Educação Profissional Técnica de Nível Médio (EPTNM), de acordo com a Sinopse Estatística da Educação (INEP, 2013), o Brasil tem 1,4 milhão de matriculados, dos quais 338 mil na oferta Integrada, 310 mil na forma Concomitante e 793 mil na oferta Subsequente. Enquanto a oferta Integrada é atendida basicamente pelas redes públicas federal, estaduais e municipais, perfazendo $92 \%$ do total das matrículas, as ofertas Concomitante e Subsequente são atendidas majoritariamente pela rede privada, com 65\% e 58\%, respectivamente. 
Esses dados suscitam questionamentos sobre como vem se dando o diálogo entre necessidades da sociedade, em particular da(s) juventude(s) e as políticas curriculares para o Ensino Médio e para a Educação Profissional Técnica de Nível Médio. Um aspecto que de certo modo se mantém presente nos últimos quase 30 anos desde os debates em torno da atual Lei de Diretrizes e Bases da Educação Nacional (LDB), Lei Federal 9.394/96, é a relação entre escola, juventude e trabalho, observando-se distintas compreensões acerca das relações entre trabalho e educação. Tomando-se por referência o contexto de redemocratização do país, que marcou as discussões sobre a LDB no período compreendido entre 1986 e 1996, identifica-se como uma das propostas presentes a concepção de formação integrada, formação tecnológica e/ou formação politécnica, frequentemente empregadas como correlatas e que, embora timidamente, encontra-se incorporada no texto da LDB.

Este texto busca mostrar aproximações e distanciamentos em relação à ideia de formação politécnica/ tecnológica/integrada em três momentos da formulação de políticas para o Ensino Médio no Brasil: no contexto da elaboração da LDB; nas proposições das Diretrizes Curriculares Nacionais para o Ensino Médio de 1998 (Parecer CNE/CEB 15/98) e para a Educação Profissional de 1999 (Parecer CNE/CEB 16/99); e nas atuais Diretrizes Curriculares Nacionais para o Ensino Médio (Parecer CNE/CEB 05/2011 e Resolução CNE/CEB 02/2012) e para a Educação Profissional Técnica de Nível Médio (Parecer CNE/CEB 11/2012 e Resolução CNE/ CEB 06/2012). A finalidade dessa discussão se ancora, principalmente, na necessidade de aprofundamento e ampliação do debate considerando as proposições presentes no Documento Referência para a realização da Conferência Nacional de Educação - Conae 2014 e as possibilidades dela decorrentes, de orientar e subsidiar a definição e a análise de políticas educacionais para esta etapa e modalidade de oferta da educação básica.

\section{Proposições do Documento Referência da Conae 2014 para o Ensino Médio e para a Educação Profissional Técnica de Nível Médio}

As concepções e propostas para o Ensino Médio e para a Educação Profissional estão explicitadas principalmente (mas não exclusivamente) no Eixo III - Educação, trabalho, desenvolvimento sustentável, saúde e meio ambiente do Documento Referência da Conae 2014. Para a presente análise, considerou-se a versão que inclui as proposições advindas das conferências municipais e estaduais constantes do texto que serviu de base para a Conferência Nacional de Educação realizada em Brasília-DF entre os dias 19 e 22 de novembro de 2014.

O Documento referência da Conae 2014 considera a educação como prática social cada vez mais ampla e presente na sociedade atual. A compreensão e formulação de propostas para a educação passa, necessariamente, conforme o Documento da Conae 2014, por considerar as transformações econômicas e políticas ocorridas na esfera mundial e local, em especial as relativas à reestruturação produtiva, à mundialização do capital e às novas formas de regulação econômica e social a elas relacionadas ${ }^{3}$ (BRASIL, 2014, p. 46).

Considerando as mudanças na configuração social do país nas últimas décadas, com ênfase para os processos que ampliaram as dificuldades de inserção dos jovens no mundo do trabalho, o agravamento do desemprego juvenil e a não inclusão de expressiva parcela da juventude brasileira no sistema educacional, o Documento Referência da Conae 2014 confere destaque ao desafio educacional associado ao desenvolvimento científico e tecnológico. Desse modo, educação, ciência, tecnologia e sustentabilidade tornam-se "elementos fundamentais nos processos de desenvolvimento econômico e social" do país (BRASIL, 2014, p. 57). Tais elementos adquirem centralidade quando se trata da definição de políticas para o Ensino Médio e para a Educação Profissional.

\footnotetext{
3 A constituição de um novo padrão de acumulação e regulação "sustenta-se em dois alicerces fundamentais que demarcam uma nova base técnica do trabalho e caracterizam a reestruturação produtiva: assenta-se na adoção de novas tecnologias que se utilizam da microeletrônica no processo de produção e de circulação de mercadorias e serviços; e, na adoção de novas formas de organização e gestão da produção inspirados que demandam participação ativa por parte do trabalhador no processo de trabalho. 0 que tem sido retratado com frequência como um movimento de reestruturação produtiva mostra-se como uma reestruturação da sociedade e que conduz a mudanças nos processos de formação para além das anunciadas como adequação ao que é requerido pelo mercado de trabalho".
} 
Com vistas a demonstrar tal centralidade, e dada a natureza e escopo deste artigo, confere-se destaque a duas formulações, destacadas por compreenderam de modo geral e substantivo, as concepções e propostas do Documento da Conae. A primeira diz respeito ao Ensino Médio de educação geral. A segunda, à Educação Profissional Técnica de Nível Médio.

247 - 8.18. Reestruturar o Ensino Médio, incentivando práticas pedagógicas com abordagens interdisciplinares, estruturadas pela relação entre teoria e prática, por meio de currículos escolares com conteúdos obrigatórios e eletivos, em dimensões como ciência, arte, trabalho, linguagens, tecnologia, cultura, meio ambiente e esporte, garantindo a aquisição de equipamentos e laboratórios, a produção de material didático específico, o reconhecimento da diversidade linguística, a formação continuada de professores e a articulação com instituições acadêmicas, esportivas e culturais (BRASIL, 2014, p. 57).

E

239 - 8.10. Garantir expandir a Educação Profissional pública de qualidade, em diferentes modalidades e níveis, na perspectiva do trabalho como princípio educativo, com financiamento público permanente, que atenda às demandas produtivas e sociais locais, regionais e nacionais, em consonância com a sustentabilidade socioambiental, com a gestão territorial e com a inclusão social, as diversidades étnico-raciais de modo a dar suporte aos arranjos produtivos locais e regionais, contribuindo com o desenvolvimento econômico-social (BRASIL, 2014, p. 56).

A seguir, faz-se um percurso analítico das proposições oficiais para a organização pedagógico-curricular para o Ensino Médio e para a Educação Profissional nas duas últimas décadas com vistas a identificar elementos que possam ter servido de referência para as formulações acima destacadas ou que caracterizem embates, controvérsias ou disputas em torno da definição dessas políticas.

\section{A LDB 9.394/96, as proposições para o Ensino Médio e a ideia de formação politécnica}

A LDB consagrou o Ensino Médio como educação básica. Este é um aspecto realmente positivo no sentido da definição de uma identidade para essa etapa educacional, em que pese não ter sido assegurada a necessária condição de obrigatoriedade. A lei define que a educação escolar deve estar vinculada ao mundo do trabalho e à prática social e que compete à educação básica possibilitar uma formação comum com vistas ao exercício da cidadania e ao fornecimento dos meios para progredir no trabalho e em estudos posteriores (art. 22).

O Ensino Médio com duração mínima de três anos possui, conforme a LDB, as finalidades de consolidação e aprofundamento dos conhecimentos adquiridos no ensino fundamental, possibilitando o prosseguimento de estudos; de preparação básica para o trabalho; de formação ética, de desenvolvimento da autonomia intelectual e do pensamento crítico do educando; de compreensão dos fundamentos científico-tecnológicos dos processos produtivos (art. 35).

Tendo em vista alcançar essas finalidades, a Lei de Diretrizes e Bases propõe que o currículo e a organização pedagógica do Ensino Médio confiram especial ênfase à educação tecnológica básica; à compreensão do significado da ciência, das letras e das artes; ao processo histórico de transformação da sociedade e da cultura; à língua portuguesa como instrumento de comunicação, acesso ao conhecimento e exercício da cidadania.

A concepção de Ensino Médio estabelecida na LDB traz, ainda que de forma pouco precisa, a incorporação da ideia de uma educação tecnológica, que deveria ser capaz de relacionar teoria e prática, mundo da ciência e mundo do trabalho, enfim, algo que se assemelha a uma formação politécnica, proposição que vinha sendo alvo das discussões entre os educadores nos anos que antecederam a elaboração da LDB, bem como nos momentos em que, a pretexto dela, realizaram-se inúmeros debates nos quais a questão da definição da identidade dessa etapa da educação básica era preocupação recorrente. Distanciando-se, no entanto, dessa compreensão ampliada, o texto final da LDB toma o trabalho em um sentido mais restrito, por vezes dimensionado como ocupação ou emprego.

No contexto de elaboração da LDB, as críticas a um Ensino Médio elitista e excludente apontavam para a necessidade de se tomar o mundo do trabalho como referência para a definição da identidade dessa etapa 
da educação básica. O conceito chave em torno do qual se articulava essa intenção era o de "politecnia", entendido, naquele contexto, como a formação humana assentada na tríade que compreende a educação intelectual, a educação do corpo e a educação tecnológica (MACHADO, 1989, p. 124).

O sentido de educação tecnológica proposta na LDB, vale ressaltar, deriva dos debates em torno da formação politécnica e significa conduzir, tal qual explicitado no corpo da lei, à compreensão dos princípios e fundamentos científicos das técnicas criadas com o fim de satisfazer as necessidades humanas nos mais diferentes contextos, tempos e espaços em que essa produção se dá. Nessa direção, a proposição presente na LDB se aproxima da ideia de formação politécnica ou tecnológica, bem como encontra ressonância nas propostas acima destacadas do Documento Referência da Conae 2014.

\section{O pós-LDB 9.394/96: as diretrizes curriculares de 1998 e 1999, a centralidade da noção de competências e o distanciamento da ideia de formação politécnica}

Entre os anos de 1995 e 2000 foram produzidos vários documentos de política que, se divergem em sua natureza - ora assumem o caráter de proposta, ora têm uma função normativa - manifestam uma mesma intencionalidade, qual seja a de produzir mudança significativa na estrutura curricular do Ensino Médio. Os principais documentos oficiais que explicitam essa intenção são: os Parâmetros Curriculares Nacionais para o Ensino Médio (PCNEM), produzidos sob orientação do MEC pela sua Secretaria de Educação Média e Tecnológica (SEMTEC); as Diretrizes Curriculares Nacionais para o Ensino Médio (DCNEM), explicitadas no Parecer 15/98 e na Resolução 3/98 da Câmara de Educação Básica (CEB) do Conselho Nacional de Educação (CNE); e, ainda, as duas formas de avaliação, o Sistema Nacional de Avaliação da Educação Básica (SAEB) e o Exame Nacional do Ensino Médio (ENEM).

A política norteadora da reforma curricular esteve articulada ao pressuposto de uma propalada necessidade de articulação entre demandas da economia e educação escolar. Esse pressuposto se mostrou ora de forma explícita, ora subsumido no interior dos dispositivos legais que fundamentaram e normatizaram a reforma do Ensino Médio no momento imediatamente após a promulgação da LDB. No que diz respeito à reforma curricular, o pressuposto da necessidade de adequação da escola média às demandas da economia traduzia-se na necessidade de mudança do paradigma curricular. De modo recorrente as proposições das DCNEM (1998) e PCNEM afirmavam que a organização do currículo com base nos saberes disciplinares tradicionais não mais responderia às demandas da esfera produtiva, especialmente no que diz respeito à formação para o mundo do trabalho. Em substituição, foi proposta a organização curricular com base na definição de competências e habilidades.

A multiplicidade de origens e significados atribuídos ao termo competências entre os diferentes dispositivos normativos culminaram em um discurso fragmentado, mas nem por isso desarticulado. A lógica que o articula está dada pelas mudanças tecnológicas e organizacionais dos processos produtivos, conforme justificativa encontrada nos textos normativos e que, no campo da educação, conduziria à homogeneização dos requisitos de formação, marcados, especialmente, pelo atendimento a demandas advindas do mercado de trabalho.

Observa-se ainda, tanto nas proposições dos PCNEM e das DCNEM, quanto nos encaminhamentos do SAEB e do ENEM, que seus formuladores partiram do pressuposto de que o emprego da noção de competências fosse algo consensual, amplamente partilhado e de conhecimento, inclusive, por parte dos que teriam que lidar com essa referência sem terem, no entanto, se envolvido com o processo de definição dessas políticas, os professores. Essa pressuposição explica, por exemplo, a fluidez e as ambiguidades presentes na maneira com que é exposta a noção de competências nas poucas vezes em que se tenta defini-la, ou nas inúmeras vezes em que é prescrita como resultado desejado da organização pedagógica-curricular (SILVA, 2008; 2012).

Deve-se lembrar que o momento histórico de homologação das diretrizes para o Ensino Médio, seja na versão para educação geral (1998), seja na versão de Educação Profissional (1999), estava marcado pela 
abertura dos mercados nacionais e pelo incentivo ao comércio internacional como estratégias de enfrentamento ao baixo crescimento econômico verificado nos anos 1980 e início dos anos 1990. Também estavam na ordem do dia os efeitos das crises econômicas do México e da Ásia. No plano econômico interno, o Brasil havia finalmente controlado a inflação e estava prestes, no plano político, a reeleger o presidente Fernando Henrique Cardoso, que capitaneava a desregulamentação econômica, com privatização de estatais e flexibilização das relações de trabalho.

Essa orientação do governo resultaria em uma nova estratégia de incorporação dos trabalhadores ao mercado, conforme mostra Ferretti (2010, p. 97):

No que diz respeito ao trabalhador, essa incorporação tende, cada vez menos, a passar pelo crivo e orientação do coletivo e cada vez mais pelas competências individuais. Isso implica uma alteração fundamental nas relações contratuais entre capital e trabalho porque, por esse processo, o lado do capital se fortalece exponencialmente, na mesma medida em que 0 do trabalho se enfraquece. As disputas contratuais tendem a ser não mais entre dois coletivos, mas entre um coletivo muito forte, a empresa, e, de outro lado, os sujeitos individuais, contratados individualmente - como antes -, mas agora sem a mediação e a cobertura do sindicato.

Esses elementos ajudam a compreender por que o discurso do sistema produtivo, preocupado com a recuperação das "perdas" e ampliação dos lucros, e maquiado pela metalinguagem da eficiência e produtividade, foi incorporado nas políticas públicas, aí incluída a educacional, gerando um especial tensionamento durante a elaboração das diretrizes para o Ensino Médio e para a Educação Profissional.

Nesse contexto, portanto, as primeiras diretrizes defendiam o "prolongamento da escolaridade e a ampliação das oportunidades de continuar aprendendo" (BRASIL, MEC, DCNEM, 1998, p. 18) e a "vinculação entre educação e trabalho, na perspectiva da laboralidade [...] para se entender o conceito de competência como capacidade pessoal de articular os saberes [...] inerentes a situações concretas de trabalho" (BRASIL, MEC, DCNEP, 1999, p. 19).

Segundo Silva (2004, p. 9), "a centralidade da noção de competências, como eixo articulador da formação e da atuação profissional desloca, para o indivíduo, a responsabilidade de assegurar as condições de ingresso e permanência no emprego". Não por acaso, durante a década de 1990 os neologismos proliferaram no âmbito das relações de trabalho, sendo o termo "empregabilidade" o mais paradigmático deles. Sua defesa é coerente com o discurso de que as incongruências, as exclusões e a marginalização dos trabalhadores não são fruto do capitalismo, mas culpa deles próprios ou da escola, quando não se preparam para enfrentar os desafios da sociedade mercantilizada.

O modo como está retratada a relação entre mudanças tecnológicas, mudanças no conhecimento e necessidade de mudanças na educação escolar ilustra a maneira pela qual os propositores desses Parâmetros e Diretrizes recaíram em um determinismo econômico que circunscreve uma visão parcial e limitada do papel da escola. Nesse contexto, a escola fica restrita à formação para o mercado de trabalho e suas finalidades vinculadas à produção econômica, ainda que afirme uma pretensa formação para a cidadania, que também se confunde com os anseios de observância à lógica do mercado.

Os argumentos apresentados permitem afirmar que tais formulações se distanciam do debate que marcou as discussões sobre o Ensino Médio no contexto da elaboração da LDB, que girou, fortemente, em torno da ideia de formação politécnica e de educação tecnológica, na acepção já explicitada. Se distanciam, igualmente, das concepções presentes no Documento Referência da Conae 2014, sobretudo no que diz respeito à formação para o mundo do trabalho. Para este documento, a educação básica, mesmo aquela que se volta para a formação profissional, não deve perder de vista o horizonte da formação tecnológica, integral e integrada por meio das dimensões do trabalho, da ciência, da tecnologia e da cultura.

Os limites das proposições das Diretrizes Curriculares de 1998 e 1999, o novo cenário político brasileiro a partir do início dos anos 2000 e os debates em torno de um novo Plano Nacional de Educação (PNE) revigoraram as discussões em torno das políticas para a educação básica. Somente, porém, ao final da década, é que se 
coloca em pauta a necessidade de revisão das diretrizes exaradas pelo Conselho Nacional de Educação. Esse processo e o contexto em que ele transcorre são tratados na seção a seguir.

\section{As novas/atuais Diretrizes Curriculares Nacionais para o Ensino Médio e Educação Profissional: tensionamentos em torno da (re)aproximação da proposta de formação politécnica}

A Emenda Constitucional n 59/2009 (BRASIL, 2009) e os Planos Nacionais de Educação (BRASIL, 2001; 2014) sinalizam na direção da universalização do acesso à última etapa da educação básica, o que implica na ampliação do financiamento e na criação de possibilidades curriculares que propiciem a atribuição de novos sentidos ao currículo e à experiência vivida na escola pelos jovens (e adultos) que a frequentam, considerando a diversidade das culturas e identidades juvenis, as necessidades e expectativas de seus sujeitos, e as demandas da sociedade atual.

Na esteira da formulação de novos cenários para o Ensino Médio estão as novas Diretrizes Curriculares Nacionais para o Ensino Médio (Parecer CNE/CEB 05/2011 e Resolução CNE/CEB 02/2012) e as Diretrizes Curriculares Nacionais para a Educação Profissional (Parecer CNE/CEB 11/2012 e Resolução CNE/CEB 06/2012).

A retomada da Educação Profissional enquanto política teve início com os Decretos $n^{\circ} 2.208 / 1997$ e $n^{\circ}$ 5.154/2004 (BRASIL, 1997, 2004) e com os pareceres e resoluções do Conselho Nacional de Educação a eles relacionados, que trataram da organização e das diretrizes da Educação Profissional Técnica de Nível Médio (EPTNM). Em ambos os casos, ressentiram-se de melhor clareza na concepção e planejamento da Educação Profissional de modo que proporcionassem o abandono dos percursos formativos fragmentados, destituídos de significado mais amplo para a formação do trabalhador, ficando claro que tais alterações "se plasmaram para que esta esfera se ajustasse aos processos de desregulamentação, flexibilização e privatização" (FRIGOTTO, CIAVATTA e RAMOS, 2005, p. 13).

A crítica que se disseminou entre os educadores que reivindicavam um itinerário formativo único e integrado, onde não houvesse separação entre Educação Profissional e Ensino Médio, prevista no Decreto n².208/1997, é que sensibilizou o governo para a incorporação, pelo seu sucedâneo 5.154/2004, da possibilidade de oferta integrada.

Assim como os decretos citados, outros dispositivos legais afetaram o percurso recente da EPTNM no Brasil, focados na melhoria dos indicadores de escolarização e "profissionalização", refletindo o esforço para elevar a imagem externa e possibilitar maior participação brasileira no mercado globalizado e na divisão internacional do trabalho, sem romper, portanto, com a lógica de conformação da educação escolar às demandas do mercado de trabalho.

Apesar do tangenciamento da educação escolar aos interesses do sistema produtivo, não é demais esperar que as políticas de Educação Profissional contribuam, ao mesmo tempo, para a conclusão da educação básica e para a inserção laboral ou melhoria das condições de ocupação e renda dos trabalhadores, sem que isso impeça o seu acesso a um Ensino Médio de qualidade, ou que obstaculize o seu avanço ao ensino superior.

Nessa perspectiva, a análise dos contextos social, econômico e político em que as diretrizes foram concebidas ajuda a compreender os avanços e limites do Ensino Médio e da Educação Profissional nas últimas duas décadas.

Ao retomar a análise dos cenários em que se construíram as diretrizes, deve-se lembrar que depois de uma década desde as primeiras versões (1998/1999), e mais de sete anos da mudança de orientação política na condução do governo federal (2003), deflagrou-se a revisão desses documentos normativos, chegandose à homologação, em 2011, das DCNEM, mediante o Parecer 05/2011 e Resolução 02/2012, e das DCNEP, mediante o Parecer 11/2012 e Resolução 06/2012, todos emanados do CNE/CEB.

No interstício de treze anos entre as versões antigas e novas, os indicadores brasileiros mostram uma melhora em geral, tanto no aspecto econômico quanto social: mesmo em tempos de alternadas crises financeiras, o Produto Interno Bruto, ainda que baixo, apresenta resultados acima da média mundial; a inflação inspira 
preocupações, mas segue controlada; os juros chegaram aos níveis mais baixos registrados na história brasileira recente e, além disso, não houve necessidade de novos empréstimos internacionais para rolar a dívida externa. Tudo isso contribuiu para melhorar a imagem do Brasil perante os países ricos e os organismos internacionais, o que não significa uma transformação qualitativa radical, haja vista o aprofundamento do fosso entre ricos e pobres e a necessidade de políticas de renda mínima, como o Programa Bolsa-Família.

É esse, portanto, em síntese, o contexto no qual foram concebidas as políticas públicas recentes, dentre as quais aquelas que procuram intervir na realidade mediante a ampliação da escolaridade da população, ganhando destaque as preocupações com o Ensino Médio enquanto etapa escolar privilegiada de mediação da relação dos filhos da classe trabalhadora com o mundo do trabalho.

As novas Diretrizes Curriculares para o Ensino Médio têm como fundamento a formação integral do estudante, o trabalho como princípio educativo e a pesquisa como princípio pedagógico; a educação em direitos humanos; a sustentabilidade ambiental como meta universal; a indissociabilidade entre educação e prática social, considerando-se a historicidade dos conhecimentos e dos sujeitos do processo educativo, bem como entre teoria e prática no processo de ensino-aprendizagem; a integração de conhecimentos gerais e, quando for o caso, técnico-profissionais realizada na perspectiva da interdisciplinaridade e da contextualização; o reconhecimento e aceitação da diversidade e da realidade concreta dos sujeitos do processo educativo, das formas de produção, dos processos de trabalho e das culturas a eles subjacentes; a integração entre educação e as dimensões do trabalho, da ciência, da tecnologia e da cultura como base da proposta e do desenvolvimento curricular.

O Ensino Médio deverá considerar o trabalho, a ciência, a cultura e a tecnologia como dimensões da formação humana e eixo da organização curricular. O texto das DCN para o Ensino Médio assim compreende essas dimensões:

$\S 1^{0} 0$ trabalho é conceituado na sua perspectiva ontológica de transformação da natureza, como realização inerente ao ser humano e como mediação no processo de produção da sua existência;

$\S 2^{\circ}$ A ciência é conceituada como o conjunto de conhecimentos sistematizados, produzidos socialmente ao longo da história, na busca da compreensão e transformação da natureza e da sociedade.

$\S 3^{\circ}$ A tecnologia é conceituada como a transformação da ciência em força produtiva ou mediação do conhecimento científico e a produção, marcada, desde sua origem, pelas relações sociais que a levaram a ser produzida.

$\S 4^{\circ}$ A cultura é conceituada como o processo de produção de expressões materiais, símbolos, representações e significados que correspondem a valores éticos, políticos e estéticos que orientam as normas de conduta de uma sociedade (Brasil, Parecer CNE/CEB 05/2011).

Essas Diretrizes estabelecem ainda que a organização curricular do Ensino Médio possua uma base nacional comum e uma parte diversificada (art. $7^{\circ}$ ) e que as mesmas não se constituem em blocos distintos, mas em um todo integrado. O currículo deverá se organizar em quatro áreas do conhecimento: Linguagens, Matemática, Ciências da Natureza e Ciências Humanas.

A compreensão dos processos sociais a partir dos significados produzidos pela articulação entre trabalho e cultura, entre ciência e tecnologia, conforme estabelecido nas Diretrizes Curriculares Nacionais para o Ensino Médio (Parecer CNE/CEB 05/2011 e Resolução CNE/CEB 02/2012; MEC, 2011 e 2012) confere uma identidade para o Ensino Médio ao propor que esta última etapa da educação básica se oriente pela busca de uma formação humana integral. A ideia de formação integral e integrada converge com as formulações em torno do conceito de formação politécnica e tecnológica e tem sido referência quando se trata de propor políticas de currículo que visem a uma organização pedagógica menos fragmentada e hierarquizada. Tais proposições resgatam o debate que vinha sendo feito acerca da identidade do Ensino Médio no contexto das discussões da atual LDB e que, pelas correlações de força daquele período, acabou enfraquecida.

Quanto às Diretrizes Curriculares Nacionais para a Educação Profissional, o primeiro texto (BRASIL, MEC, DCNEP, 1999) fazia alusão ao artigo 40 da LDBEN, prescrevendo o desenvolvimento do ensino técnico "em 
articulação com o ensino regular, ou por diferentes estratégias de educação continuada". O relator entendia que articulação indicava mais que simplesmente complementaridade:

[...] implica em intercomplementaridade mantendo-se a identidade de ambos; propõe uma região comum, uma comunhão de finalidades, uma ação planejada e combinada entre o Ensino Médio e o ensino técnico. Nem separação, como foi a tradição da educação brasileira até os anos 70, nem conjugação redutora em cursos profissionalizantes, sucedâneos empobrecidos da educação geral, tal qual a propiciada pela Lei Federal n ${ }^{0}$ 5.692/71. Mas, na sua articulação com o Ensino Médio a educação técnica deve buscar como expressar, na sua especificidade, os valores estéticos, políticos e éticos que ambos comungam (BRASIL, MEC, DCNEP, 1999, p.14-15).

Além da "intercomplementaridade" não ter se resolvido com o tempo, verifica-se que as novas diretrizes (MEC, DCNEP, 2012, p. 58) mantiveram a Educação Profissional "articulada e subsequente ao Ensino Médio, podendo a primeira ser integrada ou concomitante a essa etapa da Educação Básica", conf. art. 3․ A previsão de Educação Profissional "não integrada" ao Ensino Médio, tanto na forma concomitante quanto na forma subsequente, não é mera questão curricular ou de organização do trabalho pedagógico escolar, permitindo inferir que ao manter percursos formativos fragmentados, divididos e não integrados, a escola reproduz e aprofunda a dualidade, marca histórica quando se trata do Ensino Médio.

A manutenção da não integração reflete o percurso inicial escolhido para a elaboração das novas DCNEP pelo Conselho Nacional de Educação que não tinha como objetivo construir uma proposta pedagogicamente mais avançada e preocupada com os interesses e necessidades dos educandos, futuros trabalhadores, mas apenas ajustar o texto às últimas alterações legais:

A proposta do Parecer Cordão [...] à atualização das DCNEP, inicia-se com um histórico da Educação Profissional Técnica de Nível Médio a partir da LDB de 1996, destacando o conjunto de regulamentações provocadas pelo dec. n. 2.208/97. Curiosamente, ressalta que essas permaneceram plenamente compatíveis com o dec. n. 5.154/2004, o que teria exigido do Conselho somente sua atualização promovida pelo Parecer CNE/CEB n. 39/2004. Nesse momento, a finalidade de um novo parecer seria principalmente explicitar orientações complementares em relação a eventuais divergências, considerando, inclusive, as alterações introduzidas pela lei n. 11.741/2008 (CIAVATTA; RAMOS, 2012, p. 20, grifo nosso).

Esse percurso inicial controvertido, que começou com a apresentação de um texto já pronto, poderia ter consequências ainda mais prejudiciais, não fosse a manifestação de setores da sociedade civil, que se articularam e contribuíram com o debate por meio do documento DIRETRIZES CURRICULARES NACIONAIS PARA A EDUCAÇÃO PROFISSIONAL TÉCNICA DE NÍVEL MÉDIO EM DEBATE - texto para discussão. ${ }^{4}$

A versão oficial preliminar que circulou durante as discussões estava marcada pelo foco no desenvolvimento de competências e pela desconsideração da articulação teórico-prática da formação humana:

0 art. $6^{0}$ da Resolução CNE/CEB nº 4/99 já estabelecia que 0 desenvolvimento de competência profissional é 0 compromisso ético das instituições de Educação Profissional e Tecnológica para com seus alunos e a sociedade beneficiária de seu trabalho profissional, devendo ser entendido no sentido de promoção da "capacidade de mobilizar, articular e colocar em ação, valores, habilidades e conhecimentos necessários para o desempenho eficiente e eficaz de atividades requeridas pela natureza do trabalho" (MEC, DCNEP versão em discussão em 2011, p. 22, e posteriormente substituída, grifo nosso)5.

\footnotetext{
4 Esse texto surgiu no âmbito de Grupo de Trabalho que contou com a participação de gestores estaduais de Educação Profissional vinculados ao Conselho Nacional dos Secretários de Educação (CONSED); do Fórum dos Conselhos Estaduais de Educação; do Conselho Nacional das Instituições da Rede Federal de Educação Profissional, Científica e Tecnológica (CONIF); da Central Única dos Trabalhadores (CUT), representada pela Escola dos Trabalhadores; do Sindicato Nacional dos Servidores Federais da Educação Básica, Profissional e Tecnológica (SINASEFE); da Associação Nacional de Pós-Graduação e Pesquisa em Educação (ANPEd), e a colaboração de renomados pesquisadores da Educação Profissional e tecnológica. Também participaram, no âmbito do governo federal, quatro Secretarias do MEC, o Ministério do Trabalho e Emprego (MTE) e o Ministério da Saúde (MS), representado pela Escola Politécnica de Saúde Joaquim Venâncio (EPSJV - Fiocruz). No presente texto a autoria deste Documento será referida como Coletivo Social (BERNARDIM, 2013).

5 Trata-se da versão que circulou nos bastidores do Conselho Nacional de Educação e que foi motivo de crítica nos meios intelectuais, sofrendo inúmeras alterações até que se chegasse ao Parecer 11/2012 CNE/CEB, aprovado em 09.05.2012. As várias versões do texto das atuais DCNEP são emblemáticas do embate de concepções e das disputas em torno da definição da política curricular para a educação básica, notadamente, para 0 Ensino Médio e para a Educação Profissional Técnica de Nível Médio. A esse respeito sugere-se a leitura do artigo de Ramos, M. e Ciavatta intitulado "A 'era das diretrizes': a disputa pelo projeto de educação dos mais pobres" publicado na Revista Brasileira de Educação, v. 17, n 49, jan-abr de 2012.
} 
O maior tempo requerido para a discussão e a apreciação pela CEB/CNE parece ter sido oportuno para aprimorar o texto e eliminar trechos como o acima transcrito, que limitavam bastante as possibilidades da Educação Profissional. Apenas esse exemplo já antecipava os problemas que permaneceriam no texto dessas diretrizes, não fosse a crítica de um grande número de entidades e intelectuais preocupados com a educação dos jovens e dos trabalhadores, e que se manifestaram por meio do documento mencionado.

Logo, no interstício de treze anos entre as primeiras diretrizes e a sua recente revisão persistem preocupações, tensionamentos e controvérsias no que diz respeito à relação entre mudanças na base material, mudanças no mundo do trabalho e o direcionamento das políticas educacionais.

Outro aspecto que merece menção diz respeito a que, embora fundamental na constituição do ser humano e na construção de uma nova sociedade, a educação escolar não pode ser responsabilizada pelos problemas sociais, visto que também ela é determinada historicamente nos planos infra e superestruturais, conforme destaca o texto que faz análise crítica à versão das diretrizes apresentada pelo Conselheiro Cordão, de 2010:

[...] deve ser rejeitada a concepção que vê a educação como salvação do país e a Educação Profissional e tecnológica como a porta da empregabilidade, entendida como condição individual necessária ao ingresso e permanência no mercado de trabalho, de responsabilidade exclusiva dos trabalhadores (COLETIVO SOCIAL, 2010, p. 39).

Não se trata de negar o papel importante da escola para a formação das novas gerações e para a construção de uma sociedade justa, mas sim de relativizar o seu poder em um mundo marcado pela mercantilização das coisas e das relações.

Nesse sentido, se as DCNEM de 2012 apresentam avanços, e se aproximam das concepções e propostas do Documento Referência da Conae 2014, o mesmo não se pode dizer das DCNEP aprovadas também em 2012 , cujos aspectos mais críticos foram apontados por intelectuais, educadores e trabalhadores da educação, durante o período de sua elaboração, análise e discussão no CNE. Em síntese, os pontos mais sensíveis assinalados pelo Grupo de Trabalho anteriormente identificado e aqui denominado de Coletivo Social (2010), são:

- Centralidade formativa na dimensão econômica e aceitação do mercado como instrumento regulador da sociabilidade humana;

- Insistência no modelo de Educação Profissional centrado no desenvolvimento de competências profissionais e abandono da perspectiva de formação politécnica;

- Aceitação de uma inserção subserviente da sociedade brasileira na divisão internacional do trabalho;

- Concepção de desenvolvimento produtivista, centrado na produção destrutiva e não na socialização dos bens e distribuição da riqueza que assegurem uma vida digna a todos.

A não explicitação, no texto da resolução que homologa as atuais DCNEP, de elementos que remetam à necessidade de formação integral e integrada, da tomada do trabalho como princípio educativo, e da ciência, da tecnologia, da cultura e do trabalho como categorias orientadoras do currículo, é sintomática das dificuldades de se implementar um projeto de Educação Profissional que não esteja restrita à lógica mercantil.

Considera-se estas questões fundamentais quando o que está em disputa é o projeto de formação dos jovens e dos trabalhadores. Logo, a Educação Profissional a ser abraçada pela escola pública, de caráter universal e de concepção politécnica, ainda que carregue as marcas do tempo presente e esteja inserida na sociedade capitalista, converge com a proposição do Coletivo Social de que a escola pode e deve sinalizar para a superação de sua estreita subordinação à lógica mercantil e à racionalidade econômica.

O desvelamento das relações obscurecidas pelo sistema mercantil é o pressuposto que orienta a proposição de educação que se pretende integrada, politécnica, tecnológica, e emancipatória. Se o trabalho é central, precisa ser assimilado de modo a ultrapassar o senso comum que o vincula à mera profissionalização para o sistema produtivo e o reduz a um simulacro das possibilidades de realização das necessidades humanas. Esta é a perspectiva que está anunciada e assumida pelo Documento Referência da Conferência Nacional de Educação - Conae 2014. 


\section{A título de conclusão}

O Parecer 05/2011 do CNE/CEB parte do reconhecimento de que as novas Diretrizes Curriculares Nacionais para o Ensino Médio estão ancoradas na necessidade de conferir outra dinâmica a essa etapa da educação básica e de buscar novas formas de organização do currículo com vistas à ressignificação dos saberes escolares para que sejam capazes de conferir qualidade e ampliar a permanência dos jovens na escola. Nesse sentido, o texto normativo traz um conjunto de argumentações que buscam qualificar e contextualizar suas proposições: a educação como direito social; o Ensino Médio com qualidade social; o sentido da escola para as "juventudes"; as especificidades do Ensino Médio noturno, da educação de jovens e adultos, dos quilombolas, indígenas e do campo, os estudantes da educação especial, estão entre os argumentos que explicam as propostas para a organização curricular segundo essas diretrizes. Nesses aspectos, as atuais diretrizes para o Ensino Médio se aproximam, reiteram e valorizam as formulações constantes do Documento Referência da Conae 2014.

A indicação de afastamento do uso do termo "qualidade" no sentido da racionalidade, eficiência e produtividade, passando a ser tomado no sentido de "qualidade social", que expressa a democratização do acesso, o compromisso e a responsabilidade social, também aponta para a convergência com os interesses do público que se ressente da conclusão da educação básica, público este alçado à prioridade nos debates que culminaram com a elaboração do documento da Conae.

Nesse sentido, levando-se em conta o contexto socioeconômico em que foram concebidas, as atuais DCNEM (2012) sinalizam, em comparação com a sua versão anterior (1998), uma visão mais clara e posicionamento mais crítico quanto à necessidade de um esforço articulado entre tipos e níveis de educação, formal ou não, como resposta à educação continuada demandada pela contemporaneidade, mas não restrita ao mercado de trabalho, preocupação sinalizada reiteradamente no Documento Referência da Conae 2014.

As bases conceituais sobre as quais se ancoram as novas Diretrizes para o Ensino Médio tomam o trabalho como princípio educativo, a pesquisa como princípio pedagógico e o eixo ciência-cultura-trabalho-tecnologia como fundamento da organização pedagógico-curricular do Ensino Médio. Tais proposições recuperam a ideia de formação politécnica, presente, como mencionado, nos debates que antecederam a elaboração da atual LDB. Aqui, uma vez mais, se assevera a proximidade de concepções entre a política curricular para o Ensino Médio e as formulações que orientaram a realização da Conferência Nacional de Educação no ano de 2014.

No caso das novas Diretrizes Curriculares Nacionais para a Educação Profissional e dos pareceres e resoluções que Ihes deram caráter normativo (2011/2012), quando comparadas com a sua versão anterior (1999) e, ainda, cotejadas com a proposta de DCNEP feita pelo Coletivo Social, revelam que a manutenção de percursos fragmentados e desarticulados entre si fere os princípios de integração reivindicados para a escola politécnica. Além disso, o forte apelo de formação voltada aos interesses do mercado de trabalho sinaliza a persistência de um tangenciamento da escola aos interesses do empresariado e ao aprofundamento da divisão social do trabalho. Nesse aspecto ele se distancia significativamente das proposições presentes no Documento Referência da Conae 2014, amplamente debatidas pela sociedade brasileira ao longo das conferências municipais e estaduais, e reiteradas na Conferência Nacional de novembro de 2014.

Embora as novas diretrizes para a Educação Profissional não observem os pressupostos da educação politécnica que atenda aos anseios da(s) juventude(s), de certa forma representam avanços quanto à flexibilidade na organização curricular, introduzindo a ampliação do tempo de integralização como vantagem a ser considerada quando se leva em conta as especificidades dos alunos, em especial dos trabalhadores. Se isso não é suficiente, deve-se considerar que a Educação Profissional Técnica de Nível Médio de oferta integrada apresenta-se como alternativa historicamente viável para a última etapa da educação básica. Por essa razão se confere especial sentido e relevância para as propostas do documento base da Conae 2014. 


\section{Referências}

BERNARDIM, M. L. Juventude, escola e trabalho: sentidos atribuídos ao Ensino Médio integrado por jovens da classe trabalhadora. Curitiba: UFPR, 2013. (Tese de Doutorado).

BRASIL. Fórum Nacional de Educação. CONAE 2014. Documento Referência. Brasília, 2014. Disponível em http://conae2014.mec.gov.br/images/pdf/doc referencia.pdf. Acesso em 12 de dezembro de 2014.

Decreto $\mathbf{n}^{\circ} \mathbf{2 . 2 0 8}$, de 17 de abril de 1997. Regulamenta o $\S 2^{\circ}$ do art. 36 e os arts. 39 a 42 da Lei $n^{\circ}$ 9.394, de 20 de dezembro de 1996, que estabelece as diretrizes e bases da educação nacional. D.O.U., Brasília, 18 abr. 1997. Disponível em: www.planalto.gov.br/ccivil 03/decreto/D2208.htm. Acesso em: 10 jun. 2013.

Decreto $n^{\circ} \mathbf{5 . 1 5 4}$, de 23 de julho de 2004. Regulamenta o $\S 2^{\circ}$ do art. 36 e os arts. 39 a 41 da Lei no 9.394, de 20 de dezembro de 1996, que estabelece as diretrizes e bases da educação nacional, e dá outras providências. D.O.U., Brasília, 26 jul. 2004. Disponível em: www.planalto.gov.br/ccivil_03/_Ato2004-2006/2004/ Decreto/D5154.htm. Acesso em: 10 jun. 2013.

Emenda Constitucional $\mathbf{n}^{\circ} \mathbf{5 9}$, de 11 de novembro de 2009. Acrescenta $\S 3^{\circ}$ ao art. 76 do Ato das Disposições Constitucionais Transitórias para reduzir, anualmente, a partir do exercício de 2009, o percentual da Desvinculação das Receitas da União incidente sobre os recursos destinados à manutenção e desenvolvimento do ensino de que trata o art. 212 da Constituição Federal, dá nova redação aos incisos I e VII do art. 208, de forma a prever a obrigatoriedade do ensino de quatro a dezessete anos e ampliar a abrangência dos programas suplementares para todas as etapas da educação básica, e dá nova redação ao $\S 4^{\circ}$ do art. 211 e ao $\S 3^{\circ}$ do art. 212 e ao caput do art. 214, com a inserção neste dispositivo de inciso VI. Disponível em: http://www.planalto. gov.br/ccivil 03/constituicao/Emendas/Emc/emc59.htm. Acesso em: 23 jul. 2014.

Lei $\mathbf{n}^{\circ} \mathbf{9 . 3 9 4}$, de 20 de dezembro de 1996. Estabelece as diretrizes e bases da educação nacional. D.O.U., Brasília, 23 dez. 1996. Disponível em: www.planalto.gov.br/ccivil 03/Leis/L9394.htm. Acesso em: 10 jun. 2013.

Lei $\mathbf{n}^{\circ} \mathbf{1 0 . 1 7 2}$, de 9 de janeiro de 2001. Aprova o Plano Nacional de Educação e dá outras providências. D.O.U., Brasília, 10 jan. 2001. Disponível em: http://www.planalto.gov.br/ccivil 03/leis/leis 2001/l10172.htm. Acesso em: 23 jul. 2014.

Lei $\mathbf{n}^{\mathbf{1}} \mathbf{1 3 . 0 0 5}$, de 25 de junho de 2014. Aprova o Plano Nacional de Educação - PNE e dá outras providências.D.O.U., Brasília, 26 jun. 2014. Disponível em: http://www.planalto.gov.br/ccivil 03/ Ato20112014/2014/Lei/L13005.htm. Acesso em: 23 jul. 2014.

. Conselho Nacional de Educação. Parecer CNE/CEB n 15, de $1^{\circ}$ de junho de 1998. Trata das Diretrizes Curriculares Nacionais para o Ensino Médio. Brasília: 1998.

. Conselho Nacional de Educação. Parecer CNE/CEB n 16, de 5 de outubro de 1999. Trata das

Diretrizes Curriculares Nacionais para a Educação Profissional Técnica de Nível Médio. Brasília: 1999.

. Conselho Nacional de Educação. Parecer CNE/CEB nº 5, de 4 de maio de 2011. Trata das Diretrizes

Curriculares Nacionais para o Ensino Médio. Brasília: 2011.

Conselho Nacional de Educação. Parecer CNE/CEB n 11, de 9 de maio de 2012. Trata das Diretrizes Curriculares Nacionais para a Educação Profissional Técnica de Nível Médio. Brasília: 2012.

Conselho Nacional de Educação. Resolução CNE/CEB n 3, de 26 de junho de 1998. Institui as Diretrizes Curriculares Nacionais para o Ensino Médio. Brasília: 1998. Disponível em: http://portal.mec.gov.br/ cne/arquivos/pdf/rceb03 98.pdf. Acesso em: 25 out. 2012.

Conselho Nacional de Educação. Resolução CNE/CEB n 4, de 8 de dezembro de 1999. Institui as Diretrizes Curriculares Nacionais para a Educação Profissional. Brasília, 1999. Disponível em: http://portal.mec. gov.br/dmdocuments/rceb004 99.pdf. Acesso em: 29 set. 2013.

Conselho Nacional de Educação. Resolução CNE/CEB $\mathbf{n}^{\circ}$ 2, de 30 de janeiro de 2012. Define 
Diretrizes Curriculares Nacionais para o Ensino Médio. D. O. U., Brasília, 31 jan. 2012, Seção 1, p. 20. Disponível em: $\quad$ http://www.sinepe-pe.org.br/wp-content/uploads/2012/05/Resolucao CNE 022012 Ensino Medio.pdf. Acesso em: 10 jun. 2013.

Conselho Nacional de Educação. Resolução CNE/CEB n 6, de 20 de setembro de 2012. Define Diretrizes Curriculares para a Educação Profissional. D.O.U., Brasília, 21 set. 2012, Seção 1, p. 22. Disponível em: http://curitiba.ifpr.edu.br/wp-content/uploads/2011/06/resolu\%C3\%A7\%C3\%A3o-DIRETRIZES-EDUCACAOPROFISSIONAL-6 12-ATUAL.pdf. Acesso em: 10 jun. 2013.

MEC. Conselho Nacional de Educação. Texto preliminar das Diretrizes Curriculares Nacionais para a Educação Profissional Técnica de Nível Médio. Brasília: CNE, 2010. Texto do relator Francisco A. Cordão, que esteve em discussão entre 2011 e 2012, e foi substituído. Disponível em: http://forumeja.org.br/ sites/forumeja.org.br/files/versaopreliminaraudipublinaciona.PDF. Acesso em: 28 set. 2013.

MEC. Parâmetros Curriculares Nacionais para o Ensino Médio. Brasília: MEC, 1999.

CIAVATTA, M. A formação integrada: a escola e o trabalho como lugares de memória e de identidade. In: FRIGOTTO, G.; CIAVATTA, M.; RAMOS, M. (org.). Ensino Médio integrado: concepção e contradições. São Paulo: Cortez, 2005.

CIAVATTA, M.; RAMOS, M. A "era das diretrizes": a disputa pelo projeto de educação dos mais pobres. In: Revista Brasileira de Educação, v. 17, n. 49, jan.-abr. 2012.

COLETIVO SOCIAL. Diretrizes curriculares nacionais para a Educação Profissional Técnica de Nível Médio em debate. Texto para discussão. Brasília. 2010. Disponível em: https://www.google.com/url?sa=t\&rct=j\& $q=\& e s r c=s \&$ source $=$ web\&cd $=1 \& v e d=0 C C 0 Q F j A A \& u r l=h t t p \% 3 A \% 2 F \% 2 F p o r t a l$. mec.gov.br\%2Findex.php\%3FI temid\%3D\%26gid\%3D6695\%26option\%3Dcom docman\%26task\%3Ddoc download\&ei=6ji3UdXXHKSU0QH3 6oGABw\&usg=AFQjCNESIC wOTTz QgJ2RIvQgoLvX9MWw\&sig2=Tgsq7ao2veKIMVumWMnM3g\&bvm=bv.47 534661,d.dmQ. Acesso em: 10 jun. 2013.

FERRETI, C. J. Mudanças no âmbito do trabalho, juventude e escolhas profissionais. In: FERREIRA Cristina et al (orgs). Juventude e iniciação científica: políticas públicas para o Ensino Médio. Rio de Janeiro: EPSJV; UFRJ, 2010.

FRIGOTTO, G.; CIAVATTA, M.; RAMOS, M. (org.). Ensino Médio integrado: concepções e contradições. São Paulo: Cortez, 2005.

INEP. MEC. Sinopse Estatística da Educação Básica. 2013. Disponível em: http://portal.inep.gov.br/basicacenso-escolar-sinopse-sinopse. Acesso em 15 jul. 2014.

Censo da Educação Básica 2013. Brasília: MEC, INEP, 2014. Disponível em http://download.inep.gov. br/educacao basica/censo escolar/apresentacao/2014/apresentacao coletiva censo edu basica 022014. pdf. Acesso em 15 de dezembro de 2014.

MACHADO, L. Politecnia, escola unitária e trabalho. São Paulo, Autores Associados, 1989.

SILVA, M. R. Competências: fluidez e ambigüidades para administrar a formação do trabalhador. In: $27^{\mathbf{a}}$ Reunião Anual da ANPED, 2004, Caxambu - MG. Sociedade, Democracia e Educação. Qual Universidade? 2004, p. 01-17.

Currículo e competências: a formação administrada. São Paulo: Cortez, 2008.

Perspectivas Curriculares Contemporâneas. Curitiba: Editora Ibpex, 2012.

Tecnologia, trabalho e formação na reforma curricular do Ensino Médio. Cadernos de Pesquisa,

v. 39, n.137, p.441-460, maio/ago. 2009. Disponível em: http://www.scielo.br/scielo.php?pid=S0100$15742009000200007 \&$ script=sci arttext. Acesso em: 24 jul. 2014.

Recebido em novembro de 2014 - Aprovado em dezembro de 2014 